CORRECTION

\title{
Correction to: The role of angiopoietin-2 in nucleus pulposus cells during human intervertebral disc degeneration
}

Kun Wang, Wei Liu, Yu Song, Xinghuo Wu, Yukun Zhang, Shuai Li, Yong Gao, Ji Tu, Yingle Liu and Cao Yang

(c) The Author(s), under exclusive licence to United States and Canadian Academy of Pathology 2021

Laboratory Investigation (2021) 101:1523-1524; https://doi.org/10.1038/s41374-021-00658-7

Correction to: Laboratory Investigation; https://doi.org/10.1038/ labinvest.2017.35; published online 10 April 2017

The original version of this article unfortunately contained mistakes. The authors have noticed that:
1. In the Fig. $5 b$, on the Ang- 2 treat groups, the representative blots of gene "a $5 \beta 1$ " were mistakenly used.

2. The Fig. 5e was identical as Fig. 5d during figure assembly.

The corrected figures are shown below. The authors sincerely apologize for these mistakes in the article and are very sorry for any inconvenience. 
a
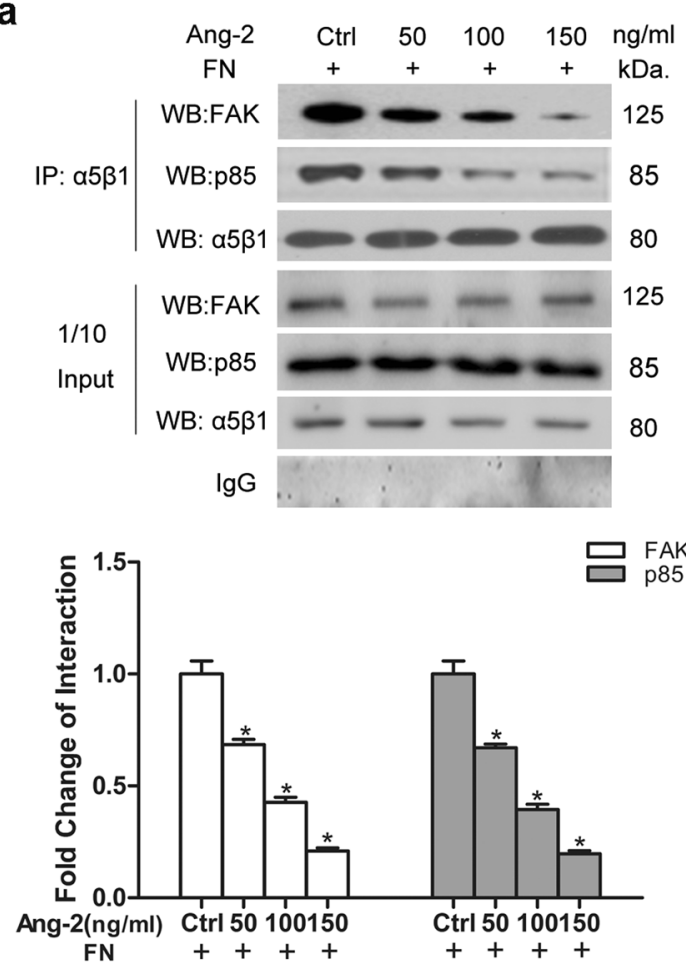

C
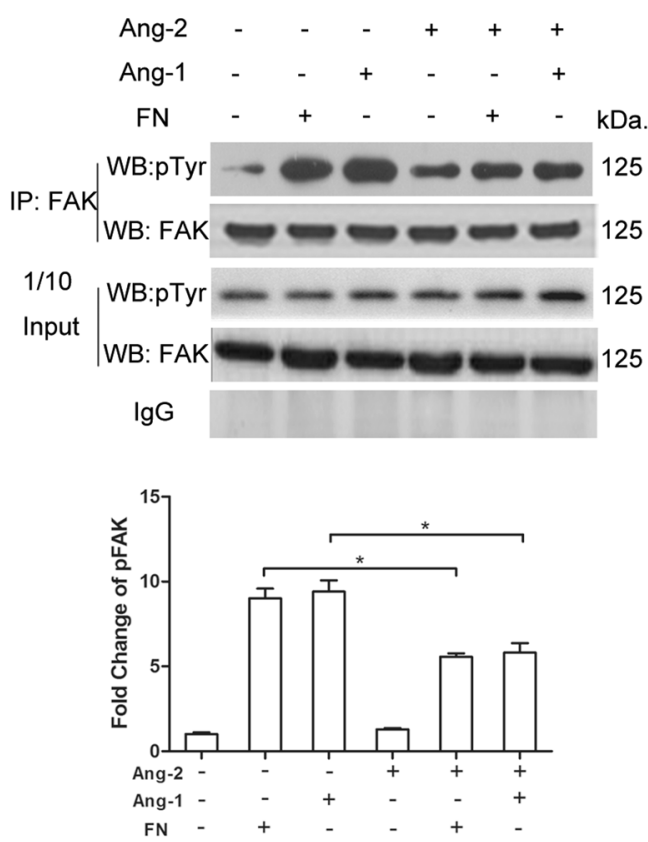

b
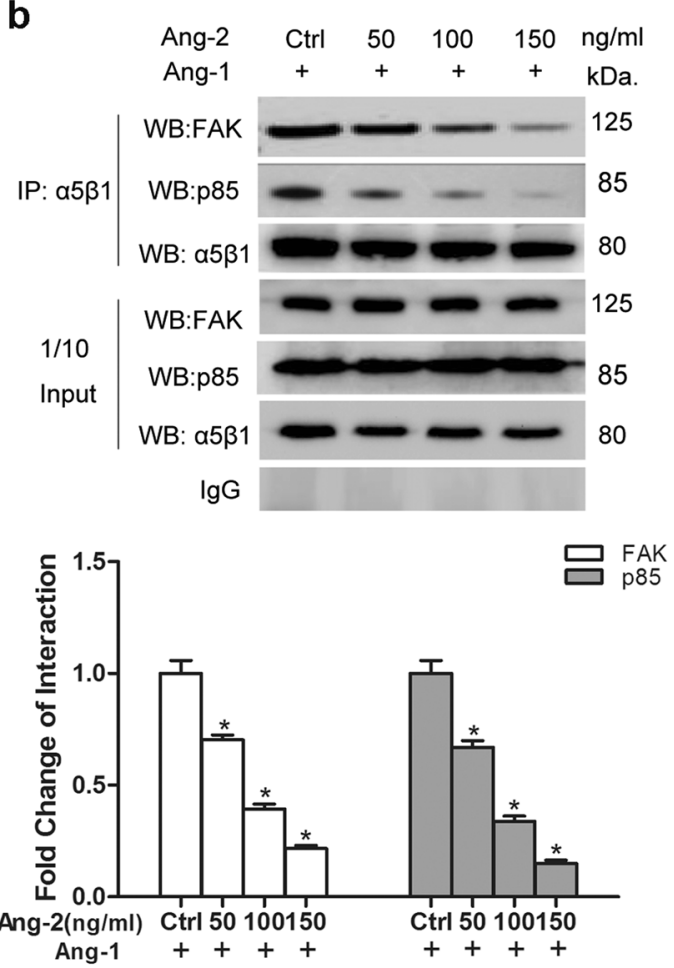

d

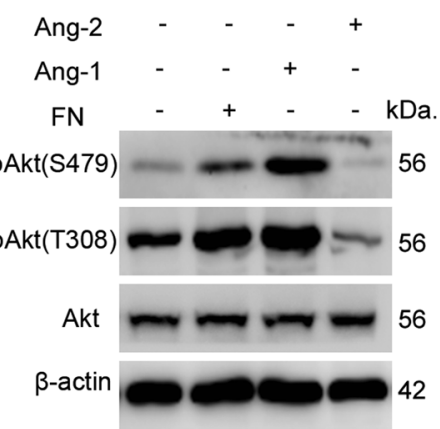

e
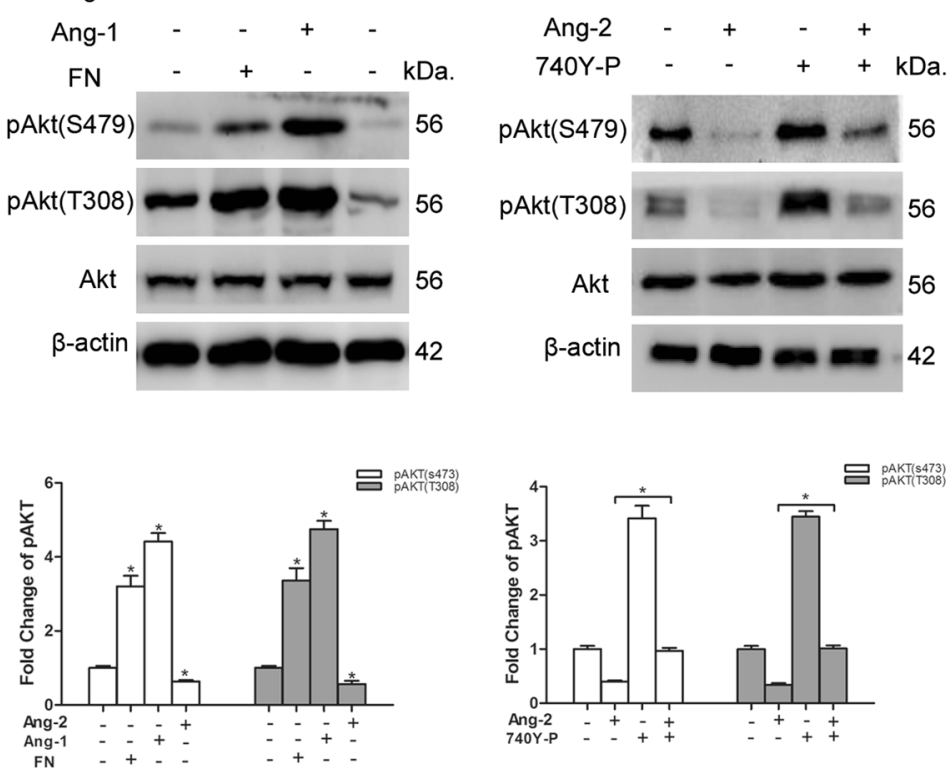